\title{
DE CUIDADORA A CUIDADA: QUANDO A MULHER VIVENCIA O CÂNCER ${ }^{1}$ FROM CARETAKERS TO TAKEN CARE OF: WHEN WOMEN FACE CANCER DE CUIDADORA A CUIDADA: CUANDO LA MUJER VIVENCIA EL CÁNCER
}

\author{
Maria Aparecida Salci², Sonia Silva Marcon ${ }^{3}$
}

\footnotetext{
${ }^{1}$ Parte da dissertação de mestrado: Enfrentando o câncer em família, apresentada ao Programa de Pós-graduação em Enfermagem da Universidade Estadual de Maringá (UEM), em dezembro de 2005.

${ }^{2}$ Mestre em Enfermagem. Professor Assistente do Departamento de Enfermagem da UEM. Paraná, Brasil.

${ }^{3}$ Doutora em Enfermagem. Professor Adjunto do Departamento de Enfermagem da UEM. Orientadora da dissertação. Paraná, Brasil.
}

PALAVRAS-CHAVE: Saúde da mulher. Neoplasias. Cuidados de enfermagem. Família.

KEYWORDS: Women's health. Neoplasms. Nursing care. Family.

PALABRAS CLAVE: Salud de la mujer. Neoplasias. Atención de enfermería. Familia.

Maria Aparecida Salci

Endereço: Avenida Colombo, 5790, bl. 01, sl. 09

87020-900 - Maringá, PR, Brasil

E-mail: mariaapsalci@bol.com.br
RESUMO: Objetivou-se com este estudo identificar como as mulheres experienciam a necessidade de receber cuidados após o diagnóstico de câncer. Como estratégia teórico-metodológica, foi utilizado o Interacionismo Simbólico e a Teoria Fundamentada nos Dados. Os dados foram coletados no período de março a novembro de 2005, junto a 20 indivíduos, sendo 10 mulheres portadoras de câncer em diferentes fases de tratamento, e seus respectivos familiares significantes os quais constituíram três grupos amostrais. Identificou-se que elas passam de cuidadoras a cuidadas, sendo que para algumas, essa foi uma experiência boa, já para outras, ter que receber cuidados é bastante desconfortável. Os cuidados recebidos estiveram relacionados com higiene pessoal, alimentação, tarefas domésticas, transporte, cuidados para com os filhos, companhia e apoio psicológico. Mesmo debilitadas fisicamente e necessitando serem cuidadas, elas não abandonam seu papel de cuidadora ao se preocuparem com o estado emocional dos membros familiares.

ABSTRACT: This study aimed to identify how women experience the need to receive care after being diagnosed with cancer. The theoretical-methodological strategies utilized were Symbolic Interacting and the Grounded Theory. Data was collected from March to November of 2005, using 20 subjects. Ten of these were women with cancer in different stages of treatment and their respective relatives, who composed three sample groups. It was identified that they go from caretakers from those who are taken care of. For some of them, it was a good experience; while for others, being taken care of was quite uncomfortable. The care received was related to personal hygiene, feeding, domestic tasks, transportation, child care, company, and psychological support. Even physically weakened and in need of care, they did not abandon their caretaker role as they were concerned with the emotional state of their family members.

RESUMEN: Este estudio tuvo por objetivo identificar cómo las mujeres experimentan la necesidad de recibir cuidados después de que se les diagnostica el cáncer. Como estrategia teórico-metodológica fue utilizado el Interaccionismo Simbólico y la Teoría Fundamentada en los Datos. Los datos fueron recogidos en el período de marzo a noviembre de 2005, junto a 20 individuos, siendo 10 mujeres con cáncer en diferentes fases de tratamiento, y sus respectivos familiares significantes, los cuales constituyeron tres grupos como muestras. Se identificó que ellas pasan de cuidadoras a cuidadas, siendo que para algunas, esa fue una experiencia buena, sin embargo, para otras, tener que recibir cuidados es bastante incómodo. Los cuidados recibidos estuvieron relacionados con la higiene personal, la alimentación, las tareas domésticas, el transporte, los cuidados con los hijos, la compañía y el apoyo psicológico. A pesar de que estén debilitadas físicamente y necesitando que sean cuidadas, ellas no renuncian a su rol de cuidadoras, preocupándose con el estado emocional de los miembros de la familia. 


\section{INTRODUÇÃO}

A diferença entre os sexos existe desde o início da humanidade, não apenas no sentido biológico, mas principalmente no social. ${ }^{1}$ As conquistas alcançadas atualmente pelas mulheres é fruto do rompimento de vários tabus impostos pela sociedade ao longo da história social, durante a qual elas vivenciaram, por muitos séculos, a submissão e a discriminação.

A despeito de todas as transformações ocorridas no papel da mulher na sociedade através das gerações, suscitando o surgimento de novas práticas relacionadas ao viver em família, a mulher continua sendo a principal responsável pela criação dos filhos. Ademais, ainda hoje, na família, é ela que detém a responsabilidade e o saber sobre o cuidado. Ela aprende em geral no convívio com outras mulheres, executa-o durante toda sua vida e transmite este conhecimento a outras mulheres, especialmente às filhas e netas. ${ }^{2}$ Esta dança na transmissão de conhecimentos que ocorre entre mulheres de diferentes gerações é que garante, em última instância, a qualidade e manutenção da vida familiar.

As mulheres, portanto, são as geradoras do cuidado e para cuidar, se organizam, fazem arranjos internos, deixam outras atividades, solicitam ajuda, em geral a outras mulheres, e assim assumem o controle, especialmente nos casos de doença e no cuidado cotidiano aos filhos pequenos e aos idosos. Isso porque o principal componente da sobrevivência humana é o cuidado que tem sido transmitido especialmente pelo trabalho da mulher com seus filhos. Aliás, o cuidado encontrase na própria raiz da história das mulheres, para assegurar a manutenção e continuidade da vida. Em todas as sociedades do mundo, as mulheres desenvolveram cuidados principalmente relacionados ao corpo e à alimentação, além de ser o elemento que cuida dos outros durante eventos especiais vida. ${ }^{3}$

Em um casal de idosos, por exemplo, é a mulher, esposa, que cuida do marido, embora muitas vezes a filha solteira ou mais próxima (outra mulher) substitua ou auxilie a mãe no cuidado dos irmãos ou do pai, quando esta já se encontra um pouco debilitada. Para as mulheres, tornar-se cuidadoras é um processo natural, embora não exista rodízio na execução dos cuidados e tão pouco auxílio de outras pessoas. ${ }^{2}$

O tornar-se cuidadora de um membro familiar acometido por doenças, é um processo quase que natural, mesmo para mulheres idosas e com limitações. Elas fazem isto com dedicação, apesar das dificuldades econômicas por terem deixado de trabalhar e do fato de serem portadoras de doenças crônicas como a hipertensão arterial, diabetes, osteomusculares, entre outras, pois percebem a função de cuidar como uma missão dignificante, envolta em princípios morais e religiosos. ${ }^{4}$

Os cuidados são desenvolvidos por elas tanto no âmbito físico como emocional e psicosocial, mesmo que com poucas informações sobre a magnitude deste cuidar e até mesmo sobre a doença em questão. A ação cuidadora é permeada de dificuldades nas atividades básicas de manutenção da vida, uma vez que são realizadas concomitantemente ao cuidado da casa, resultando numa jornada contínua e solitária de um único integrante da família - a mulher. Para superar o desgaste e a solidão, as cuidadoras buscam a rede de apoio e solidariedade, mas esta se revela provisória e com pouca capacidade de atender às carências constantes do cuidado. ${ }^{5}$

Contudo, se faz necessário ressaltar que embora os papéis prescritos para a atuação da mulher no interior da família foram se modificando, devido principalmente à sua inserção crescente no mercado de trabalho, trata-se mais de uma ampliação de papéis assumidos pela mulher do que de uma mudança propriamente dita, uma vez que ela assumiu novos papéis profissionais, mas não deixou de desempenhar uma série de funções dentro de casa, as quais de certa forma garantem o funcionamento e a própria existência da família. ${ }^{6}$

Portanto, o papel da mulher enquanto elemento de cuidado na família não é assumido só nas situações de doença, em seu cotidiano ela está o tempo todo cuidando. No domicílio, ela está sempre disponível às solicitações dos seus familiares, nos cuidados com a higiene, na alimentação, no tratamento dos enfermos e no autocuidado. ${ }^{6} \hat{E}^{\prime}$ evidente que o papel de cuidadora da mulher é conseqüência do processo de socialização que ela sofre na própria família, já que esta é a responsável pela socialização educativa e social, mas também, pela divisão sexual do trabalho, cuja tipologia organizativa baseia-se em diferenças de gênero, moldando os limites da estrutura familiar. ${ }^{7}$

Não é por outra razão que a função de cuidadora é assumida com tanta naturalidade pelas mulheres, que às vezes, nem se dão conta de que, ao desempenharem uma infinidade de ações do cotidiano relacionadas com a alimentação, o vestir, o estudo, a compra de mantimentos, entre outras, 
elas estão, antes de mais nada, "cuidando". São estas diferentes formas de manifestação do cuidar que fazem da mulher o centro deste processo no seio familiar. ${ }^{8}$

Diante do exposto, podemos observar que historicamente o cuidado sempre norteou a vivência cotidiana das mulheres, seja com seus entes queridos ou com outros ao seu redor, levando-nos ao seguinte questionamento: o que ocorre na vida familiar quando é a mulher que precisa de cuidados? Neste sentido, o objetivo deste estudo foi identificar como as mulheres experienciam a necessidade de receber cuidados após o diagnóstico de câncer.

\section{TRAJETÓRIA METODOLÓGICA}

Estudo do tipo exploratório, de natureza qualitativa que adotou o Interacionismo Simbólico (IS) como referencial teórico e a Teoria Fundamentada nos Dados (TFD) como referencial metodológico. O IS é uma perspectiva teórica centrada na interação humana, segundo o qual os seres humanos agem conforme os significados que atribuem às coisas. ${ }^{9} \mathrm{E}$ a TFD tem como propósito construir um modelo teórico que facilite o entendimento dos fenômenos sociais, a partir da perspectiva dos sujeitos investigados. Para desenvolver este modelo, utiliza-se um conjunto de procedimentos sistemáticos de coleta e análise dos dados, os quais ocorrem concomitantemente. A formalização teórica da realidade em observação é fundamentada nos próprios dados por ele gerados. ${ }^{9}$

O estudo foi realizado no município de Maringá - PR, no período de março a novembro de 2005. Os dados foram coletados junto a $10 \mathrm{mu}-$ lheres portadoras de câncer e seus respectivos familiares significantes, constituindo-se três grupos amostrais. O primeiro grupo foi constituído por cinco mulheres que estavam realizando tratamento radioterápico, o segundo, por três mulheres que haviam apresentado metástase e estavam realizando o segundo tratamento radioterápico, sendo que uma delas já havia constituído o primeiro grupo e foi também incluída neste e o terceiro, por três mulheres que haviam passado por tratamento há mais de cinco anos. Na composição dos grupos, foram respeitados os critérios de amostragem e saturação teórica. ${ }^{9}$

Amostragem teórica é o processo no qual o pesquisador após coletar, codificar e analisar os dados de cada grupo amostral, toma algumas decisões em relação a quais tipos de dados ainda devem e/ou precisam ser coletados e onde os mesmos podem ser encontrados e, a saturação teórica, é o momento no qual não são mais encontrados dados novos ou adicionais em determinado grupo, constituiu um dos principais critérios para a definição do momento em que novos grupos deveriam ser buscados. ${ }^{9}$

As mulheres do estudo tinham idade de 27 a 50 anos, com níveis de escolaridade e social diversos, sendo que quatro cursaram até o ensino fundamental, duas o ensino médio e quatro o superior e, embora não nos importasse a localização da doença, mas sim o significado atribuído a ela, houve predomínio do câncer de mama (oito casos) em diferentes estágios de tratamento. Como familiares entrevistados, tivemos quatro filhas, duas irmãs, dois esposos, uma mãe e uma prima.

O contato com as mulheres ocorreu a partir dos registros em uma clínica de radioterapia. O primeiro contato para solicitação de participação no estudo foi por telefone ou na própria clínica. A partir daí, realizou-se as entrevistas abertas, no domicílio em dia e horário pré-agendados. A questão inicial que norteou essas entrevistas foi - "O que mudou em seu contexto familiar após o diagnóstico de câncer?".

Após a transcrição e incansáveis leituras, iniciou-se o processo de codificação aberta e categorização dos dados. Utilizando o método comparativo constante, procedeu-se o agrupamento de códigos substantivos que tinham a mesma natureza, surgindo daí as categorias. Em seguida, procurou-se descobrir os principais problemas da "cena social" com vistas à construção da estrutura conceitual, a partir de um processo indutivo que inclui redução, ampliação seletiva da literatura e exemplificação seletiva dos dados, segundo o qual, novos dados são coletados de maneira seletiva para auxiliar no desenvolvimento de hipóteses e identificar as propriedades das categorias principais e avançar na construção da teoria, reforçando alguns aspectos e aprofundando o entendimento de outros. ${ }^{10}$

O projeto de pesquisa foi aprovado pelo Comitê Permanente de Ética em Pesquisa com Seres Humanos da Universidade Estadual de Maringá, Parecer $\mathrm{N}^{\circ}$ 045/2005. Para assegurar o sigilo das informantes, utilizamos nomes fictícios.

A análise dos dados permitiu a identificação do fenômeno central: "Enfrentando o câncer em família", construídos por três processos - Descobrindo a doença; Percebendo mudanças após o diagnóstico de câncer; Tendo que conviver com o câncer. Neste artigo será apresentada parte do segundo processo. 


\section{A EXPERIÊNCIA DE PASSAR DE CUIDA- DORA A SER CUIDADA}

Ao receber o diagnóstico de câncer, a mulher e sua família passam por experiências antes nunca vivenciadas, em que ocorrem mudanças em vários aspectos da vida entre eles os relacionados aos cuidados.

Assim, descobrindo-se uma portadora de câncer, em algum momento das fases que envolvem o tratamento e a evolução da doença, a mulher pode se deparar com alterações que fazem-nas precisar de cuidados e da ajuda de outras pessoas. Seus relatos permitiram identificar que antes de descobrir o câncer, todas eram cuidadoras assíduas independente do fato de trabalharem ou não fora de casa e do estágio de desenvolvimento de sua família, e ao se deparar com o diagnóstico, elas passaram à condição de precisar ser cuidada.

A vivência desta situação permitiu a identificação de duas categorias - "Um momento especial da vida: recebendo cuidados da família" e "Quando surge a necessidade não é só a família que cuida: tendo que aceitar ajuda de outros".

\section{Um momento especial da vida: recebendo cuidados da família}

Frente a essa nova situação de ter que receber cuidado, algumas mulheres se sentiram amparadas, conceituando como verdadeiros e naturais os cuidados que receberam de suas famílias.

É, eu acho que é uma coisa normal, pois o estado que en estava, eu precisava de ajuda, mas en me recuperava bem, começava a me alimentar de novo e foi bom, foi ótimo, porque você fica mais carente, precisa de apoio, então foi isso, eles me deram todo o apoio que eu precisava (Tânia).

Ah, é bom... você saber que as pessoas se preocupam com você. Porque minha família é assim, nós somos em poucos, mas nós somos bem unidos (Camila).

Quando as mulheres referiam ter sido cuidadas, elas se reportavam também aos componentes mais próximos e não apenas aos elementos da família nuclear (pais, mãe e filhos). É interessante observar que, em alguns casos, primos mais chegados e amigos próximos também foram referidos como sendo da família. Em outras situações, com filhos ainda pequenos, essas mulheres consideraram os integrantes da "família ampliada" como importantes e com papel significante ao desempenho do cuidado.

Ana Maria mencionou que além dos cuidados, receber carinho e atenção era o que ela mais precisava naquele momento, demonstrando alegria ao verificar que os familiares a atendiam com satisfação.

Dessa parte eu gostei muito, eu acho que eu estava precisando sabe, eu estava muito me dando para as pessoas, cuidando das pessoas, quando não era de um era de outro... Foi uma fase que eu senti que as pessoas me amavam que eu era importante na vida delas. Eu não me sinto mal, claro que se fossem pessoas estranhas, mas minha mãe, meus irmãos, minhas amigas de infância. Parece um mimo, é como se eu tivesse em um aniversário que não acabasse, porque eles fazem de tudo por mim, pegam na minha mão, se eu abrir o olho a noite elas estão ali, sentados, 'Ana como é que você está? Você vai melhorar força, vamos!' Então, eu só tenho que agradecer a Deus mesmo, louvar e agradecer a Deus, tanta gente sofre sem ter ninguém para cuidar, sem ter uma família, sem ter o que comer de diferente, então eu tenho que glorificar, porque eu tenho tudo isso... (Ana Maria).

A importância do apoio familiar em situações de doença, é abordado com freqüência na literatura. Ao entrevistar mulheres em tratamento quimioterápico sobre o apoio recebido de seus familiares verificou-se que após o diagnóstico de câncer, o apoio e a atenção advinda da família, representou para elas segurança e força para enfrentar o tratamento. ${ }^{11}$

Outro estudo pontuou que após o diagnóstico de câncer, houve fortalecimento dos laços familiares e isto foi muito importante para amenizar o sofrimento nos momentos que o doente mais precisava, ressaltando que os familiares estão dispostos a fazerem qualquer coisa que venha a favorecer o doente, porque se sentem responsáveis e solidários pelo mesmo. ${ }^{12}$

Assim, a família proporciona cuidados relacionados com alimentação, transporte, companhia e para com a filha pequena, ocupações que antes da doença cabia à mulher.

Minha prima que trabalha comigo, minha mãe, a minha tia, minha irmã, foram pessoas que sempre estavam ali, na quimioterapia, me levavam ao médico de carro, e me buscavam, estavam sempre ali dentro, que eu não queria ficar sozinha, estavam sempre ali do meu lado conversando comigo e quando eu precisava de alguma coisa diferente para comer, eu não precisava nem pedir quando eu pensava já estava ali, cuidavam da minha filha... (Ana Maria).

Olha... eu passei muito mal com as quimioterapias e minha mãe me ajudava muito, meu marido, minha irmã, tinha dias que minha mãe fazia comida para mim, tinha que trazer sopa, porque eu não conseguia comer nada. Me ajudavam... (Tânia). 
Tanto a saúde física quanto a emocional dos familiares ocupam um importante papel no contexto familiar, sendo os membros da família interconectados e interdependentes uns dos outros. Assim, na ocorrência de mudanças na saúde de um dos seus integrantes, todos os demais são afetados e a família como um todo passa por mudanças, "pode-se dizer que ela afeta a saúde do indivíduo e que a saúde dos indivíduos afeta a família". 13:16

O cuidado também pôde ser oferecido pela filha adolescente que se esforçava em apreender as tarefas domésticas que até então eram realizadas pela mãe.

E minha menina! Ela tem dezesseis anos, ela faz igual, ou melhor do que uma mãe. Eu falo: "não sei como é que você agüenta", eu morro às vezes só de olhar ela fazendo isso eu choro [emociona-se]. Como ela é diferente das outras meninas, que responsabilidade que ela já tem. Às vezes ela está com tudo preparado para sair, ela fala para as amigas: "eu não vou sair, hoje eu vou ficar com a minha mãe..." (Maria Santa).

Na época, eu não sabia fazer comida, nada. E de uma hora para outra tive que ajudar a assumir a casa, fazer comida, dava banho na minha mãe, aprendi a mexer no dreno dela... (Filha de Alessandra).

Em um estudo com familiares de mulheres com câncer de mama, identificou-se que essa doença tem a capacidade de provocar alterações na dinâmica familiar como um todo, e que a família, diante das situações que precisam vivenciar ao deparar-se com o câncer, utiliza-se dos potenciais de cada membro para alcançar a estabilidade do contexto familiar. ${ }^{14}$

A família conhece a mulher e consegue identificar suas angústias, e nesse momento tenta estruturar suas vidas para suprir as lacunas existentes e mantê-la emocionalmente tranqüila.

Tem essa necessidade de ter alguém ali do lado dela, preocupado, perguntando você está bem, está precisando de ajuda, quer alguma coisa? Acho que é isso que ela está necessitando e querendo agora, eu não estou tendo tempo de fazer isso agora, trabalho até de noite, eu queria um tempo para ficar com ela, mas eu não tenho, não tenho, não é porque não quero é porque eu não tenho tempo mesmo, é por isso que eu estou tentando falar com meu pai para deixar eu sair do serviço para ficar com ela, eu tenho que arriscar, mais para frente arrumo ou tro serviço, eu estou nova ainda... (Filha de Nathália).

Os familiares, ao terem um membro portador de câncer, assumem papéis antes nunca desempenhados, visando atender às necessidades do paciente com conseqüente melhoria de sua qualidade de vida. ${ }^{12}$ Assim, às vezes um membro da família em especial pode assumir todas as responsabilidades maternas para com uma criança pequena, que embora saudável requer cuidados em tempo integral, visto que os demais membros familiares acabam por voltar sua atenção para a mulher doente.

Às vezes, eu pegava a filha dela, ela não podia pegar a filha dela no colo, levava para minha casa, cuidava e brincava e ficava final de semana. Porque a menina é uma criança ela não entendia aquilo ali em volta da mãe dela, e ninguém queria saber da criança, queria saber dela. Então a criança ficava meio que de lado, então tinha que fazer o papel de mãe, colocava para dormir, levava para brincar, dava banho, ninguém nem se preocupava com a menina, porque a criança estava com saúde... (Prima de Ana Maria).

A família é uma unidade cuidadora de seus membros, sendo a principal responsável e determinante das ações que serão executadas com seu membro que se encontra acometido por alguma doença. ${ }^{15}$

Outro tipo de cuidado que emergiu dos relatos foi a companhia. Alguns familiares perceberam que esta é muito importante para a mulher, mesmo que ela não solicite, fazendo-se presentes o máximo que podem.

[...] mesmo sem ter precisão nas radioterapias eu ia com ela, porque eu acho que para ela era importante pensar que tinha alguém junto com ela, pensar 'oh, eu estou doente, estou assim, mais eu não estou sozinha, minha irmã está comigo', porque você pode ver que lá, sempre tem alguém com alguém. Então numa hora dessas, além da doença a pessoa fica muito carente, então eu deixava tudo e ia lá com ela, e era bom para mim porque eu também estava aprendendo alguma coisa e para ela estava servindo de um apoio - "não aqui está minha irmã", por isso que eu fiz tudo isso... (Irmã de Nair).

Por outro lado, a impossibilidade de estar com o ente querido, acompanhando-o nas sessões de radioterapia, gera preocupação nos familiares.

[...] começa a radio e todo mundo fica preocupado, não tem ninguém para ir com ela, não tem ninguém para estar acompanhando, ficar do lado dela, aí acho que isso atrapalhou, meu pai fica bem preocupado por causa disso, ele quer estar do lado dela, mas não tem como, ele tem que trabalhar, eu também quero, mas não tem como... (Filha de Nathália).

As alterações enfrentadas pelos familiares da pessoa com câncer são em resposta a vários 
fatores peculiares de cada membro, destacando as características de personalidade de cada indivíduo, sua capacidade de enfrentar situações de crise, a relação de proximidade com a pessoa doente, as histórias prévias de mortes vivenciadas na família, assim como a maneira como elas foram enfrentadas e o papel que a pessoa acometida pela doença ocupa dentro do contexto familiar. ${ }^{16}$

Neste sentido, a família é de grande importância para a vida do indivíduo em todos os aspectos da vida social, emocional, psicológico e afetivo. Pois esse é o espaço indispensável para a garantia da sobrevivência de desenvolvimento e da proteção integral dos filhos e demais membros. É a família que proporciona os aportes afetivos e, sobretudo materiais necessários ao desenvolvimento e bem-estar dos seus componentes. Ela desempenha um papel decisivo na educação formal e informal, é em seu espaço que são absorvidos os valores éticos e humanitários e onde se aprofundam os laços de solidariedade. ${ }^{17: 12}$

Quando surge a necessidade não é só a família que cuida: tendo que aceitar a ajuda de outros

Muitas vezes os arranjos familiares e as dificuldades que permeiam os relacionamentos não permitem que a família manifeste sua solicitude em relação aos cuidados que as mulheres necessitam neste momento em que se encontram fragilizadas física e psicologicamente pelo câncer. No entanto, quando as pessoas que se dispõe a realizar os cuidados não pertencem ao seio familiar, algumas mulheres se sentem constrangidas ao recebê-los, o que nos faz interpretar que dentro da família o ato de cuidar dos membros se encontra implícito.

Olha, eu não gostava muito, às vezes você se sente um pouco incomodada de estar pedindo as coisas para os outros. Não, não foi muito agradável não, mas você sabe que não tem outro jeito, não tem outra maneira, então você tem que aceitar aquilo ali... (Mônica).

Em um estudo sobre a vivência da hipertensão arterial quando a doente é a mulher, foi evidenciado que as complicações da doença e suas seqüelas constituem-se em temor pelo fato de leválas a pensar em receber cuidados permanentes, e tornarem-se dependentes de outras pessoas. ${ }^{18}$

Maria Santa por sua vez, já não se sentiu incomodada com relação a esse aspecto e refere ter recebido inclusive cuidados de higiene de amigas próximas.
Receber cuidados foi ótimo! E, na realidade, não foram os parentes, mas foram os amigos que são próximos, famílias maravilhosas que a gente tem mais do que parente. Assim, vamos tomar banho; entram no banheiro, lava e esfrega os pés, tudo... (Maria Santa).

Alessandra também recorda que recebeu cuidados dos amigos e também não teve nenhum constrangimento com a situação. A rede de apoio social oferecido por amigos costuma ser bastante eficiente na vivência com o câncer, pois além de contribuir como suporte emocional também auxilia no cuidados diários. ${ }^{19}$

[...] tive uma amiga que me ajudou muito na época, eu ficava na casa dela. Teve fases que eu fiquei pior fisicamente e ela me levava para casa dela, e eu gostava porque lá eu ficava isolada, depois do tratamento eu não queria barulho e no prédio era garagem, criança gritando, então, uns dois dias eu ficava lá e ela paparicando... Tive até cuidados de amigas que foram e fizeram meu serviço, depois eu arrumei uma moça, mas tiveram ali junto, conversávamos, foi muito bom... (Alessandra).

Em um estudo com mulheres mastectomizadas, constatou-se que estas trazem à situação suas características particulares de vida, sua condição médica e suas estratégias de enfrentamento para lidar com o estresse, principalmente o relacionado à doença. Porém, quando elas possuíam famílias coesas e colaborativas, enfocando aspectos positivos para lidar com o problema, isso refletia em um maior nível de bem-estar psicológico, favorecendo a que elas reassumissem os papéis sociais que desempenhavam na família e na comunidade antes do diagnóstico. ${ }^{20}$

$O$ fato de serem mulheres independentes que assumem suas responsabilidades sozinhas, constitui em fator que dificulta a aceitação da condição de dependência. Isto porque elas parecem não ter paciência para esperarem a disponibilidade de outras pessoas. Notamos no relato abaixo que passar por essa situação é algo aceitável, mas não agradável.

[...] eu sempre fui assim, o que eu tenho que fazer, eu fazia não esperava por ninguém, é difícil você ficar dependendo dos outros, você ficar esperando, você pedir, você fica..., apesar das pessoas..., tudo bem muitas chegavam e falavam para mim o que eu precisasse poderia contar tudo, mas assim é um pouco meio esquisito, sei lá, é chato, mas a gente fazer o que? A gente tem, a gente precisa, tem que acabar concordando com isso...(Mônica).

De fato, é comum as mulheres, mesmo em situação de doença se preocuparem com as tarefas cotidianas, os que as levam a exprimir 
sofrimento por não conseguirem desenvolvê-las da mesma forma que antes. ${ }^{21}$

Para outras mulheres, receber cuidados das pessoas em geral e, em especial, de amigos é bom, porém o simples fato de ter que pedir as coisas e esperar pela boa vontade dos cuidadores, a deixam incomodadas e angustiadas.

Olha, para mim é bom, quando eles fazem as coisas, só que eu não gosto de ficar pedindo nada, eu acho que isso é um defeito que eu tenho, de não gostar de ficar pedindo as coisas para os outros. Eu acho assim, que se eu tiver que fazer alguma coisa para você eu vou e faço, não precisa você ficar me pedindo, eu não gosto disso, não gosto de ficar pedindo as coisas não, então, tem hora que ichiii... eu me sinto mal, não gosto de pedir (Nathália). A mulher é uma cuidadora por excelência, existindo nela o compromisso pela vida e, especialmente, o provimento da vida do outro. Sendo assim, um estudo realizado com mulheres hospitalizadas portadoras de câncer, observou que, além do estresse da hospitalização, elas carregam a culpa por estarem ausentes do lar e do cuidado para com a família. ${ }^{21}$

O cuidado que as mulheres desenvolvem com o ser humano constitui-se em um aprendizado adquirido socioculturalmente, sendo desempenhado por elas aos seus membros familiares. ${ }^{18}$ Assim, mesmo acometidas pelo câncer, elas tentam se reorganizar para continuar assumindo suas funções dentro do contexto familiar.

A teoria desenvolvida "Enfrentando o câncer em família" revelou que esta experiência é envolta por sucessivos acontecimentos e, que o processo "percebendo mudanças após o diagnóstico de câncer" mostra não apenas a percepção das mudanças físicas, mas principalmente a percepção de mudanças de natureza psicológicas e sociais no contexto familiar, o qual é marcado pela fragilidade da mulher ao vivenciar essa nova condição, a de estar no mundo com câncer.

Neste contexto, são evidenciadas a mobilização da família, incluindo parentes e amigos próximos, para apoiar e cuidar desta mulher. Esta participação é tão importante e significativa para elas que foi possível identificar que o fenômeno central desta experiência é marcado pelo enfrentamento em família, demonstrando assim, que embora vivenciada de forma singular por cada uma das mulheres, ao vivenciar esta experiência, elas normalmente não estão sozinhas, pois um conjunto de atitudes e processos é desencadeado com o intuito de oferecer o suporte necessário para que elas superem as dificuldades do tratamento do câncer.

\section{CONSIDERAÇÕES FINAIS}

As alterações fisiológicas e emocionais enfrentadas pelas mulheres após um diagnóstico de câncer caracterizam um momento único em suas vidas, marcado principalmente pelo fato de elas constituírem o foco do cuidado no contexto familiar. Ao experienciar este novo acontecimento em suas vidas, elas fazem adaptações em seu cotidiano, decorrentes principalmente do fato de que agora elas precisam e desejam receber ajuda e cuidados de outras pessoas.

Os cuidados recebidos estiveram relacionados com higiene pessoal, alimentação, tarefas domésticas, transporte, cuidados para com os filhos pequenos e até o simples fato de permanecer como companhia a elas.

Quando o cuidado é dispensado por alguém da própria família, ele é percebido como natural pela maioria das mulheres e por esta razão, muitas sentiram-se amparadas, referindo que os cuidados recebidos foram positivos, pois reconhecem que realmente era isso que estavam precisando naquele momento. No entanto, quando o cuidado é proveniente de pessoas de fora da família, em alguns casos as mulheres sentem-se incomodadas, especialmente nos casos em que existe dependência de cuidados físicos. Elas se sentem constrangidas em terem que solicitar cuidados aos amigos e se chateiam em ter que esperar pela disponibilidade de tempo do outro.

Porém, mesmo debilitadas fisicamente e tendo que deixar de oferecer o cuidado físico aos membros familiares devido à trajetória vivida pelos tratamentos, às vezes, longos e incapacitantes, as mulheres na sua grande maioria, sofrem por deixarem outras pessoas assumirem suas responsabilidades - tarefas que antes do diagnóstico do câncer eram executadas exclusivamente por elas no contexto familiar. Assim, muitas ainda continuam assumindo o seu papel de cuidadora, ao se preocuparem com o estado emocional dos membros familiares.

Assim, este estudo faz com que os profissionais da enfermagem reflitam sobre as carências e anseios da mulher com câncer, pois esses vão muito além das necessidades físicas. Dessa forma, cabe a todos os profissionais da enfermagem conhecer a realidade da mulher com câncer e as mudanças ocorridas a partir da vivência da doença, para que possam dar apoio emocional, orientar, respeitar e ajudar a direcionar o novo modo de viver a partir do câncer a todos os envolvidos no cuidado da mulher, sendo eles familiares ou amigos. 


\section{REFERÊNCIAS}

1 Spindola T. Mulher, mãe e... trabalhadora de enfermagem. Rev Esc Enferm USP. 2000 Out-Dez; 34(4):354-61.

2 Resta DG, Budó MLD. A cultura e as formas de cuidar em família na visão de pacientes e cuidadores domiciliares. Acta Sci Health Sci. 2004 Jan-Jun; 26(1):53-60.

3 Ospina MDE, Soto ACP. Entre el rito y rutina: el rol de cuidadoras em las mujeres de Medellín. Invest Educ Enferm. 2001 Sep-Dez; 19(2):58-65.

4 Gonçalves LHT, Alvarez AM, Sena ELS, Santana LWS, Vicente FR. Perfil da família cuidadora de idoso doente / fragilizado do contexto sociocultural de Florianópolis-SC. Texto Contexto Enferm. 2006 Out-Dez; 15(4):570-7.

5 Sena RR, Silva KL, Rates HF, Vivas KL, Queiroz CM, Barreto FO. O cotidiano da cuidadora no domicílio: desafios de um fazer solitário. Cogitare Enferm. 2006 Mai-Ago; 11(2):124-32.

6 MarconSS, Elsen I. Os caminhos que, ao criarem seus filhos, as famílias apontam para uma enfermagem familial. Ciênc Cuid Saúde. 2006 Nov; 5(supl):11-8.

7 González JS. Estructuras sociales, división sexual del trabajo y enfoques metodológicos. La estructura familiar y la función socio-sanitaria de la mujer. Invest Educ Enferm. 2007 Jan-Jun; 25(1):66-73.

8 Fernandes AFC, Mamede MV. O surgimento do câncer de mama na visão de um grupo de mulheres mastectomizadas. Texto Contexto Enferm. 2004 JanMar; 13(1):35-40.

9 Glaser BG, Strauss AL The discovery of Grounded Theory: strategies for qualitative researsh. Chicago (IL): Aldine Publishing; 1976.

10 Stern PN. Grounded theory methodology: its uses and process. Indianopolis (IN): Image; 1980.

11 Molina MAS. Percepção de portadores de câncer sobre o apoio recebido dos familiares após o diagnóstico. Ciênc Cuid Saúde. 2003 Set; 2(supl):185-6.

12 Bielemann VLM. Uma experiência de adoecer e morrer em família. In: Elsen I, Marcon SS, Silva MRS, organizadoras. O viver em família e a interface com a saúde e a doença. $2^{\mathrm{a}}$ ed. Maringá (PR): EDUEM; 2004. p.199-215.

13 Angelo M, Bousso RS. Fundamentos da assistência à família em saúde. In: Brasil. Ministério da Saúde. Manual de enfermagem. Brasília (DF): Ministério da Saúde, 2001. p.14-7.

14 Biffi RG. A dinâmica familiar de um grupo de mulheres com câncer de mama. [tese]. Ribeirão Preto (SP): Universidade de São Paulo. Escola de Enfermagem; 2003.

15 Elsen I. Cuidado familial: uma proposta inicial de sistematização conceitual. In: Elsen I, Marcon SS, Silva MRS, organizadoras. O viver em família e a interface com a saúde e a doença. $2^{\mathrm{a}}$ ed. Maringá (PR): EDUEM; 2004. p.19-28.

16 Santana ADA. Cuidados paliativos ao doente oncológico terminal em domicílio: representações sociais da família. [dissertação] Salvador (BA): Universidade Federal da Bahia. Escola de Enfermagem; 2000.

17 Ferrari M, Kaloustian SM. Introdução: a importância da família. In: Kaloustian SM, organizador. Família brasileira: a base de tudo. São Paulo (SP): Cortez, UNICEF, 2004.

18 Cereser HL. A vivência da hipertensão arterial na família: quando o doente é a mulher. In: Elsen I, Marcon SS, Silva MRS. O viver em família e a interface com a saúde e a doença. $2^{\mathrm{a}}$ ed. Maringá (PR): EDUEM; 2004. p. 251-64.

19 Coyne E, Borbasi S. Holding it all together: breast cancer and its impact on life for younger women. Contemp Nurse. 2007 Jan-Mar; 23(2):157-69.

20 Gimenes MGG. A mulher após a mastectomia: alternativas para a intervenção psicológica. In: Gimenes MGG, organizadora. A mulher e o câncer. Campinas (SP): Livro Pleno, 2000. p.149-72.

21 Carvalho MVB, Merighi MAB. A mulher com câncer fora de possibilidade de cura e as diferentes faces da dor. Prática Hospitalar. 2004 Set-Out; 4(35):79-85. 